\title{
Financial Sector Reform and Its Impact on Investment and Economic Growth: An Econometric Approach
}

\author{
M. Aynul Hasan, Ashfaque H. Khan and S. SAJid Ali
}

\section{INTRODUCTION}

The financial sector is central to economic development as it serves the role of intermediary by mobilising savings and subsequently allocating credit for productive activities. However, in many developing countries including Pakistan, administered interest rate, domestic credit controls, high reserve requirements, use of captive banking system to finance large budgetary requirements of the government and controls on international capital inflows have remained the main features of the monetary policy. These repressive policies had their repercussions in the form of excess liquidity with the banking system, disintermediation of cash flows, segmentation of financial markets, underdeveloped money and capital markets, etc. [McKinnon (1973) and Shaw (1973)], therefore, argued that low interest rate ceilings unduly restrict the real flow of loanable funds, thus depressing the quantity of productive investment.

Financial liberalisation, on the other hand, is defined as policy measures designed to deregulate certain operations of the financial system and transform its structure with a view to achieving a liberalised market oriented system with an appropriate regulatory framework. The financial sector reforms would lead to increase in loanable funds by attracting more household savings to bank deposits due to higher interest rates. This, in turn, would result in greater investment and faster economic growth.

In Pakistan, various measures have been undertaken in the early 1990s to liberalise the financial sector as part of the overall structural adjustment programme (SAP) with the objective to improve the effectiveness of monetary policy. These policies were implemented by making a shift from direct to indirect monetary control and greater reliance on market forces. The main financial liberalisation policies were aimed at liberalising interest rates, reducing controls on credit, enhancing competition and efficiency in the financial system, strengthening the

M. Aynul Hasan is Professor of Economics at Acadia University, Canada. Ashfaque H. Khan is Joint Director at the Pakistan Institute of Development Economics, Islamabad. S. Sajid Ali is Economist at the State Bank of Pakistan, Karachi. 
supervisory framework, promoting growth and deepening of the financial markets. In this context, the following measures have already been implemented to date as part of the broader financial sector reforms:

- Efforts have been made to enhance the health of and competition within the banking sector by privatising two nationalised banks, as well as allowing 11 new scheduled commercial banks to be set up in the private sector.

- Debt management reforms were introduced to promote primary and secondary securities markets. The prudential supervisory framework has been established to foster sound credit decisions.

- Interest rate rationalisation was introduced by paring down concessional and direct credit schemes.

- The exchange and payment reforms have also been undertaken in the areas of foreign investment and foreign trade.

The adoption of these measures would give way to greater flexibility in the interest rate movements, an enhanced role for the market forces in credit allocation, gradual deepening of the money and securities markets, and enhancing competition and efficiency in the financial system. Against this background, the paper develops and estimates a medium-sized 24-equation macroeconometric model for the financial sector of Pakistan. The model provides a detailed consistent treatment of financial variables by disaggregating the financial assets held by the households, private business and enterprises. The behaviour of demand for these assets is then linked with the overall national saving and, subsequently, with investment and gross domestic product (GDP). This model will be useful device in not only generating $e x$ ante forecasts but, more importantly, it will provide answers to numerous interesting and critical counterfactual policy questions in the context of Pakistan's financial sector reforms. For example, if the reforms had to take place in the early eighties rather than the nineties, the model will quantitatively estimate the counterfactual loss foregone in terms of lower GDP, savings and investments in Pakistan. It is expected that these counterfactual policy simulation results may be useful to the policymakers in designing more accurate and practical future monetary policies in Pakistan.

\section{A MODEL FOR FINANCIAL SECTOR}

While the financial sector reform is initiated by bringing about changes within the monetary sector only, the impact of such a reform, however, is expected to be multifacit and wide-ranging influencing many other sectors of the economy. A single equation approach, in this context, to evaluate the implication of this reform may not only be inadequate but, at the same time, it could even be misleading. This is due to the fact that, with a single equation approach, an increase in the interest rate for 
deposit, for instance, may show a greater demand for time deposits. But in terms of total financial assets, the impact of such a change on it may be ambiguous because of the possibilities of substitution among other financial assets (e.g., currency, unfunded debt, floating debt and permanent debt).

Thus, in order to examine the intra as well as inter sectoral impact of financial sector reforms, we have constructed a medium-sized 24-equation macroeconometric model for Pakistan. The model is not only dynamic and rich in specifications but, more significantly, it is based on a pragmatic approach, which takes into account some of the specific institutional arrangements present in the financial sector of Pakistan. Broadly, the model has been divided into five blocks, namely monetary, savings, government revenue, macroeconomic and definitional blocks. In the following, we present the model without discussion so as to conserve the space. ${ }^{1}$

\section{A. Monetary Block}

\section{Net Financial Assets}

$$
N F A=C C+T D+U F D B T+\overline{F D E B T}+\overline{P D E B T}-L
$$

\section{Currency in Circulation}

$$
C C / N F A=f\left(Y / N F A, \overline{R D}, \overline{R U}, \overline{R F}, \dot{P}_{g}^{e}\right)
$$

\section{Total Deposit}

$$
T D / N F A=f\left(Y / N F A, \overline{R D}, \overline{R U}, \overline{R F}, \dot{P}_{g}^{e}\right)
$$

\section{Unfunded Debt}

$$
\text { UFDBT/NFA }=f\left(Y / N F A, \overline{R D}, \overline{R U}, \overline{R F}, \dot{P}_{g}^{e}\right)
$$

\section{Demand for Loan}

$$
L=f\left(C P, \bar{R}_{A}\right)
$$

\section{Price Level}

$$
P_{g}=f\left(T D / Y, I T R / Y, P_{m}\right)
$$

\section{Net Interest Bearing Financial Assets}

$$
T I B F A=N F A-C C
$$

${ }^{1}$ Detailed discussion can be found in Hasan et al. (1996) 
B. Savings Block

8. Savings in Real Assets

$$
\mathrm{RSA}=\mathrm{f}\left[(\mathrm{YR}-\mathrm{DTR} / \mathrm{Pg}),\left(\mathrm{RD}-\dot{P}_{g}\right), \mathrm{TD} / \mathrm{Y}, \overline{R_{m}}\right]
$$

9. Real Financial Assets

$$
R F S=\triangle T I B F A / P_{g}
$$

10. Real National Savings

$$
R N S=R S A+R F S
$$

C. Government Revenue Block

\section{Direct Taxes}

$$
D T R=f(Y)
$$

12. Indirect Taxes

$$
I T R=f(Y, M)
$$

13. Total Tax Revenue

$$
G T R=D T R+I T R
$$

\section{Total Revenue}

$$
G R=G T R+\overline{G N T R}+\overline{S_{U R}}
$$

D. Macroeconomic Block

15. Private Investment

$$
I_{p}=f\left(\overline{R A}, T D / Y, P_{m} / P_{g}, I I N F S I\right)
$$

16. Private Consumption

$$
C P=f\left[\left(Y R-D T R / P_{g}\right), \overline{R_{m}}, \overline{R D}\right]
$$

17. Public Investment

$$
I_{g}=f\left(G R / P_{g}, \overline{R F A}\right)
$$

18. Public Consumption

$$
C_{g}=f\left(G R / P_{g}\right)
$$




\section{Import}

$$
M R=f\left(Y R, P_{m} / P_{g}\right)
$$

20. National Income

$$
Y_{R}=C_{P}+I_{P}+C_{g}+I_{g}+\overline{\Delta S T}+\bar{X}-M_{R}
$$

21. Public Infrastructure

$$
I I N F=I_{g}-I_{g o}
$$

\section{Index of Public Infrastructure}

$$
I I N F S T=\left[(\overline{I I N F S}(-1)+I I N F) / \overline{I I N F S_{0}}\right]
$$

\section{National Income at Current Prices}

$$
Y=Y R \times P_{g} / 100
$$

\section{Imports at Current Prices}

$$
M=M R \times P_{m} / 100
$$

\section{List of Variables}

$$
\begin{aligned}
C C & =\text { Currency in Circulation } \\
C_{g} & =\text { Public Consumption Expenditure } \\
C_{p} & =\text { Private Consumption Expenditure } \\
D T R & =\text { Direct Taxes } \\
F D E B T & =\text { Floating Debt } \\
G N T R & =\text { Non-tax Revenue } \\
G T R & =\text { Total Tax Revenue } \\
I_{g} & =\text { Public Investment } \\
I I N E S I & =\text { Index of Economic Infrastructure Investment } \\
I I N F & =\text { Public Infrastructure } \\
I I N F S_{O} & =\text { Initial Stock of Real Public Infrastructure Investment } \\
I_{P} & =\text { Private Investment } \\
I T R & =\text { Indirect Taxes } \\
L & =\text { Loan } \\
M & =\text { Imports at Current Price } \\
M_{R} & =\text { Real Imports } \\
N F A & =\text { Net Financial Assets } \\
P D E B T & =\text { Permanent Debt } \\
\dot{P}_{g} & =\text { Expected Rate of Inflation }
\end{aligned}
$$




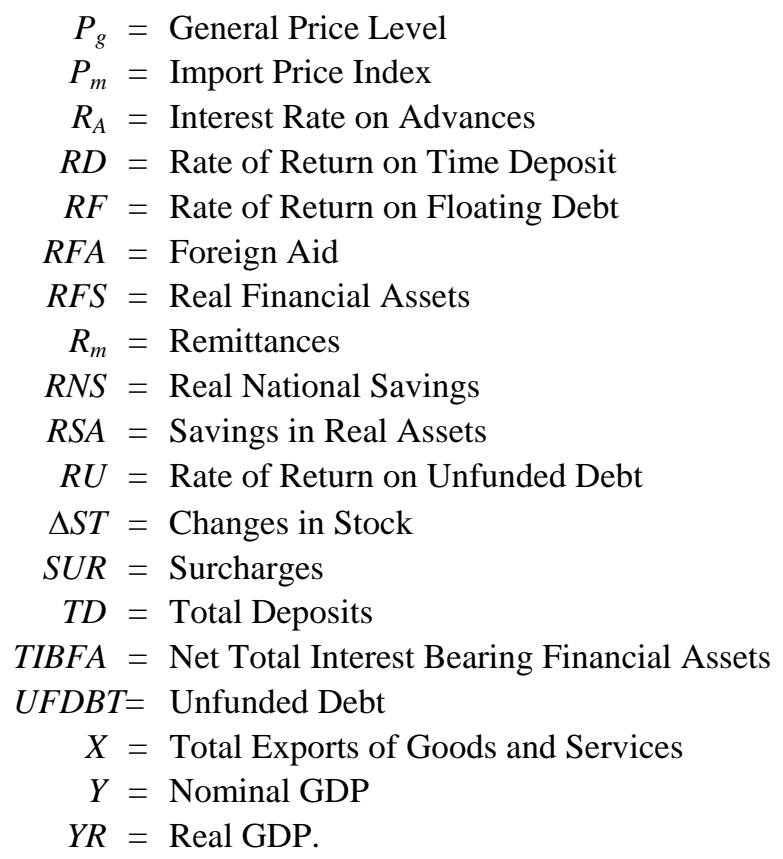

\section{RESULTS}

The results are discussed in the following paragraphs. Given the existence of long-run relationship, based on PP cointegration test, we used a simple OLS technique to estimate the behavioural equations of the model. ${ }^{2}$ By and large, all the estimated regression equations have high adjusted $R^{2}$ and significant $t$-values with correct signs implying that the individual equations not only explain the postulated behaviour well in the model but, at the same time, individual stipulated parameters can be meaningfully interpreted. Based on other estimated statistical tests (e.g., LM, $\mathrm{ARCH}$, and CUSUM), we can safely argue that the estimated regression equations are free from the statistical problems of serial correlation, heteroscedasticity and instability of the parameters.

Based on the estimated equations of the model the policy simulation exercise undertaken in this paper is essentially counterfactual in character. The key objective in carrying out this type of exercise is to investigate and unfold the conundrum as to what would have happened in Pakistan, in terms of the impact (measured by key economic variables) and the ensuing monetary cost (or loss of revenue in the form of investment and output), had this country introduced the reforms earlier in the

\footnotetext{
${ }^{2}$ The estimated regression coefficients of the model and various test statistics are available on request from the authors.
} 
eighties rather than later as done so in the nineties. In order to cover the broader aspects of the financial reform and, at the same time, keeping the discussion more manageable, we report results of the impact of three categories of policy simulation on key selected macroeconomic variables. Furthermore, for each type of policy simulation, we also calculate the corresponding expected loss of revenue (in rupees) due to late implementation of the reforms. The three broad categories of reform considered are:

1. Interest Rate Liberalisation;

2. Spread Reducing Reform; and

3. Financial Deepening.

In the following, we discuss the results of these policy simulations.

\section{Interest Rate Liberalisation}

As a result of repressive monetary policies pursued in Pakistan, the real deposit rates remained negative most of the time during the decade of the 1980s. This type of policy is expected to make non-bank assets relatively more attractive than the bank deposits thus creating financial disintermediation. In order to test the sensitivity of the above policy reforms, we conduct two types of simulation. Firstly, we keep the nominal deposit rates at least as high as 14 years (1981-94) of average inflation rate. This implies that, on average, the real rate of deposits during this period should be nonzero thus enabling the real return on financial assets to be non-negative. The second type of policy simulation in this regard entails the nominal deposit rates to be at least two percentage point above the 14 years (1981-94) average inflation rate making the real rate positive by two percentage point. The cost of late implementation of the reform is evaluated in terms of loss in real private investment and real GDP. The cost of late implementation in rupee term is reported in Tables 1 and 2.

In the first case when real return on financial assets are assumed non-negative Pakistan's economy could have avoided a loss of almost Rs 12 billion in real GDP on cumulative basis since 1980-81 as shown in Table 1. In fact, if the rate of return on deposits were allowed to be 2 percentage point above the 14 years average inflation rate (implying 2 percent positive real return on deposit), the economy could have saved a loss of Rs 78 billion in real GDP on cumulative basis or Rs 6 billion on average each year since 1980-81 as shown in Table 2.

\section{Spread-reducing Reform}

Another key impediment to the financial sector reform was the government policy of maintaining a large spread between the deposits and the lending rates of the banking system. Under the spread-reducing financial policy simulation, we have 
Table 1

Simulation Results of Interest Rate Liberalisation

(Real Return on Deposit in Non-negative)

\begin{tabular}{ccc} 
& & (Rs in Million) \\
\hline Year & $\begin{array}{c}\text { Real Private Investment } \\
\text { (Cumulative) }\end{array}$ & $\begin{array}{c}\text { Real GDP } \\
\text { (Cumulative) }\end{array}$ \\
\hline $1980-81$ & 223 & 2748 \\
$1981-82$ & 418 & 4937 \\
$1982-83$ & 368 & 4171 \\
$1983-84$ & 560 & 6878 \\
$1984-85$ & 492 & 5742 \\
$1985-86$ & 417 & 4592 \\
$1986-87$ & 363 & 3773 \\
$1987-88$ & 640 & 8457 \\
$1988-89$ & 867 & 12869 \\
$1989-90$ & 742 & 9936 \\
$1990-91$ & 1076 & 15534 \\
$1991-92$ & 1060 & 15066 \\
$1992-93$ & 941 & 13152 \\
$1993-94$ & 840 & 11749 \\
Cumulative Average & 106 & 1341 \\
\hline
\end{tabular}

Note: Cumulative values are simply the sum of successive marginal values of each year.

Table 2

Simulation Results of interest Rate Liberalisation

(Real Return on Deposit is 2 Percent)

\begin{tabular}{ccc} 
& & (Rs in Million) \\
\hline Year & $\begin{array}{c}\text { Real Private Investment } \\
\text { (Cumulative) }\end{array}$ & $\begin{array}{c}\text { Real GDP } \\
\text { (Cumulative) }\end{array}$ \\
\hline $1980-81$ & 709 & 8215 \\
$1981-82$ & 1339 & 14951 \\
$1982-83$ & 1642 & 18303 \\
$1983-84$ & 2232 & 26038 \\
$1984-85$ & 2467 & 28835 \\
$1985-86$ & 2703 & 32076 \\
$1986-87$ & 2910 & 35058 \\
$1987-88$ & 3434 & 43364 \\
$1988-89$ & 3886 & 51826 \\
$1989-90$ & 3923 & 52039 \\
$1990-91$ & 4617 & 63100 \\
$1991-92$ & 5044 & 68446 \\
$1992-93$ & 5406 & 73345 \\
$1993-94$ & 5746 & 77743 \\
Cumulative Average & 483 & 5960 \\
\hline
\end{tabular}

Note: Cumulative values are simply the sum of successive marginal values of each year. 
analysed the impact of keeping the differences between the deposit and lending rates at 2 percent on private investment and real GDP. The results, as reported in Table 3, suggest that Pakistan could have saved Rs 22.7 billion in term of loss in real GDP on cumulative basis or Rs 1.65 billion per year since 1980-81.

Table 3

Simulation Results of Spread Reducing Reforms

(Difference between the Average Lending and Deposit Rate is 2 Percent)

\begin{tabular}{lcc}
\hline & $\begin{array}{c}\text { Real Private Investment } \\
\text { (Cumulative) }\end{array}$ & $\begin{array}{c}\text { Real GDP } \\
\text { (Cumulative) }\end{array}$ \\
\hline $1980-81$ & 238 & 1849 \\
$1981-82$ & 496 & 3784 \\
$1982-83$ & 727 & 5395 \\
$1983-84$ & 953 & 7165 \\
$1984-85$ & 1178 & 8843 \\
$1985-86$ & 1381 & 10333 \\
$1986-87$ & 1541 & 11179 \\
$1987-88$ & 1719 & 12465 \\
$1988-89$ & 1860 & 13209 \\
$1989-90$ & 2010 & 14156 \\
$1990-91$ & 2237 & 16306 \\
$1991-92$ & 2466 & 18074 \\
$1992-93$ & 2723 & 20358 \\
$1993-94$ & 2992 & 22697 \\
Cumulative Average & 222 & 1645 \\
\hline
\end{tabular}

Note: Cumulative values are simply the sum of successive marginal values of each year.

\section{Financial Deepening}

Another interesting policy simulation conducted in this study pertains to the impact of financial deepening on the economy. Financial deepening in this context implies a broadening of the monetary base in relation to the real sector of the economy. The basic premise underlying such a reform is that making the financial sector wider and covering larger sectors of the economy will facilitate economic activity and may improve physical investments as well as total output of the economy. This simulation was implemented by increasing the financial deepening variable (TD/Y) by 25 percent as compared to its actual value. Promoting financial deepening policies in the early eighties rather than in the nineties could have saved Pakistan's economy up to about Rs 260 billion in terms of loss in real GDP on cumulative basis or Rs 16.6 billion per year on average basis since 1980-81 (see Table 4). 
Table 4

Simulation Results of Financial Deepening (Financial Deepening Variable Increased by 25 Percent)

\begin{tabular}{ccc}
\hline & Real Private Investment & (Rs in Million) \\
Year & 1652 & $\begin{array}{c}\text { Real GDP } \\
\text { (Cumulative) }\end{array}$ \\
\hline $1980-81$ & 3153 & 17482 \\
$1981-82$ & 4237 & 32283 \\
$1982-83$ & 5795 & 43720 \\
$1983-84$ & 6867 & 62451 \\
$1984-85$ & 8081 & 74999 \\
$1985-86$ & 9256 & 90955 \\
$1986-87$ & 10848 & 106965 \\
$1987-88$ & 12306 & 129702 \\
$1988-89$ & 13156 & 154636 \\
$1989-90$ & 15092 & 169028 \\
$1990-91$ & 16830 & 196951 \\
$1991-92$ & 18553 & 217529 \\
$1992-93$ & 20262 & 239716 \\
$1993-94$ & 1416 & 260489 \\
Cumulative Average & 16616 \\
\hline
\end{tabular}

Note: Cumulative values are simply the sum of successive marginal values of each year.

\section{CONCLUDING REMARKS}

While the significance of financial reforms in Pakistan introduced in the early 1990s cannot be undermined in that it has brought about some real changes in terms of freeing interest rates, reducing the spread rates between the deposit and lending rates, privatisation of nationalised banks, and many more, what is, however, important from the public policy point of view in this context is to know how much Pakistan's economy could have saved or gained had the reform been introduced earlier in the 1980s. Analysis of this nature which is also known as counterfactual exercise is useful not only in terms of getting an estimate of foregone benefits of delaying reforms in the past but, more importantly, it provides the policy-makers with a better insight into successfully implementing the reform in the future.

With this perspective in mind, this study develops and estimates a 24-equation medium-sized macroeconometric model for Pakistan with a specific focus on the financial sector. Although the model constructed does not explicitly deal with specific institutional arrangements (privatisation, NBFI, etc.) and management side (prudential regulations, competitions, etc.), of financial reforms, analysis of this paper, nevertheless, quantifies some of the important implications of the reform 
within the context of policy simulation exercise. Three important areas of financial reform where this study has made some modest contribution are the ones that relate to identifying the impact of more flexible market determined interest rates; reducing the spread between the deposit and lending rates; and finally, promoting policies to improve financial deepening in the economy.

In general, our findings suggest that the impact of all three financial sector reform policies not only reduce financial disintermediation (McKinnon-Shaw Hypothesis) but the positive influence also permeate into the real sector. In fact, the key finding of this study is that had Pakistan introduced the financial sector reforms in the eighties rather than in the nineties, the economy could have enhanced its output in real terms by over Rs 16.5 billion every year. This figure is by no means a trivial amount given the size of the average annual real output of Rs 344 billion during this period (1981-94).

\section{REFERENCES}

Hasan, M. Aynul, Ashfaque H. Khan and S. Sajid Ali (1996) Financial Sector Reform and its Impact on Investment and Economic Growth: An Econometric Approach. The Pakistan Development Review 35:4.

McKinnon, R. I. (1973) Money and Capital in Economic Development. New York: Oxford University Press.

Shaw, E. S. (1973) Financial Deepening in Economic Development. New York: Oxford University Press. 